\title{
Study of Current Situation and Development Strategy of Talent Resources in Athletic Gymnastics in Shaanxi Province
}

\author{
Jian Zhao*
}

Gymnastic Department, Xi'an Physical Education University, Xi'an 710068, Shanxi China

\begin{abstract}
This paper studied the current situation of the talent resource in Athletic Gymnastics in Shaanxi Province of PRC with reference to data and by methods of investigation \& visit, expert interview and mathematical statistics, etc. The research revealed that there is shortage of high-level athletes, coaches and referees in the field of gymnastics in Shaanxi Province with its level lower than the national average level and the age structure and academic status is not reasonable, either. It was advised that the reform of mechanism for talent resources in Athletic Gymnastics shall be deepened and the relevant innovation shall be strengthened in Shaanxi Province to create excellent development environment for talents; the building of reeducation, reemployment and guarantee mechanism for high-level athletes shall be strengthened; the exchange and cooperation among talents of Athletic Gymnastics shall be enhanced and the development strategy of efficient integration of human resources shall be promoted.
\end{abstract}

Keywords: Athletic gymnastics, development strategy, Shaanxi province, talent resources.

\section{INTRODUCTION}

Talent resource is the decisive factor in the development of competitive sports. On one hand, the talent resource of Athletic Gymnastics is one type of human resources of the society. It involves the knowledge, skill, ability and quality of all the personnel employed by sports organizations to develop competitive sports activities. On the other hand, it possesses the characteristics unique to competitive sports. It's relatively more typical of scarcity and mobility compared to other types of human resources [1-3]. After the obtaining of best achievements by China in the 2012 Olympic Games, the cause of national sports has developed rapidly [4-6]. This brings about new and higher requirements for the development and management of sports talents in the western Shaanxi Province, especially of talents of gymnastics. In order to adapt to the increasingly fierce competition in the field of sports in future and to keep up with the trend in the development of competitive sports, we must develop more excellent talents in athletic gymnastics $[7,8]$. Consequently, we must grasp the spirit of the central committee of CPC in the talent work conference, and do a good job in the development of talents in athletic gymnastics. Only in this way can we achieve the shift of Shaanxi Province from the "Big Province of Gymnastics" to the "Strong Province of Gymnastics".

\section{CURRENT SITUATION OF TALENT RESOURCES IN ATHLETIC GYMNASTICS IN SHAANXI PROV- INCE}

The sports talents are the key resource in promoting and achieving the sustainable development of the course of sports in Shaanxi Province [9, 10]. The talents of athletic gymnastics refer to the talents in the field of athletic gymnastics who are employed specially to take part in sports training and competitions of gymnastics. In narrow sense, the talents of athletic gymnastics can be divided into three types, the athletes, coaches and referees respectively.

\subsection{Analysis of Current Situation of Athletic Gymnastics in Shaanxi Province}

Athletes are the core elements of competitive sports. It is the athletes that embody and show the level of sports through their performance and scores they achieve. Therefore, maximizing the potential of the athletes is the fundamental guarantee of successful competitive sports. The investigation and statistics show that in 2014 there are only 136 high-level gymnasts in training (male $59 \&$ female 77 ). Among them there are 59 males and 77 females, accounting for $43.4 \%$ and $56.6 \%$ respectively. In addition, there is some kind of gap in respect of the ratio of proportion of males and female gymnast. Among them there are just one international sports master, accounting for $0.73 \%$; six national sports master, accounting for $4.41 \%$; and 121 national first- and secondlevel athletes in training, accounting for $89 \%$. The reserve of sports talents is huge but there's shortage of sports masters, fewer than the western provinces of Gansu and Guizhou. At the same time the statistics in the number of high-level gymnasts in training during the last five years (2010-2014) in Shaanxi Province (as shown in Table 1) reveals that the number of high-level gymnasts decreases every year, which raises alarm for the development and management of talent resources in athletic gymnastics.

\subsubsection{Analysis of Academic Structure}

Education is an important factor of influencing the growth of the athletes as well as their re-employment after retirement. 
Table 1. Number of gymnasts in training of Shaanxi province (2010-2014).

\begin{tabular}{|c|c|c|c|c|c|}
\hline Level & 2010 & 2011 & 2012 & 2013 & 2014 \\
\hline International Sports Master & 1 & 2 & 1 & 1 & 1 \\
\hline National Sports Master & 9 & 9 & 10 & 7 & 6 \\
\hline National First-level Athlete & 46 & 45 & 43 & 49 & 48 \\
\hline National Second-level Athlete & 70 & 69 & 68 & 72 & 73 \\
\hline Others & 18 & 15 & 16 & 10 & 8 \\
\hline Total & 144 & 140 & 137 & 139 & 136 \\
\hline
\end{tabular}

Practice has proved that the athletes with higher diploma and level of knowledge tend to understand perform better. They have little difficulty in the change of their careers after retirement and they are more likely to become excellent couches. The sports of gymnastics are very unique for the athletes start training when they are four or five years old and retire after they grow up, which makes the sports of gymnastics "the program of youth". Besides, there is the problem associated with the mechanism. All these factors result in the phenomenon among the team of elite athletes in China that their cultural and knowledge level is generally lower than their technical level in sports. The overall situation in Shaanxi province is more severe than that in other provinces. By the end of 2014 among the high-level gymnasts in Shaanxi Province there are just one athlete holding the diploma of college or above, accounting for $0.73 \%$, lower than the national average level by nearly 3 percentage points. Most of them (81 persons) hold the diploma of middle school, accounting for $59.6 \%$, and 40 persons hold the diploma of primary school, accounted for $29.4 \%$. However, according to the characteristics of athletes in re-employment and the demand for high diploma due to social development, the average educational level of the athletes shall reach the level of college or above for them to adapt to meet the needs of social development. In view of this requirement, highlevel athletes in Shaanxi Province are far from satisfying the requirements.

\subsubsection{Analysis of Age Structure}

The competitive sports is the career of youth. The highlevel athletes are very young in average. As shown in Table 2 below, the age structure of high-level gymnasts in Shaanxi Province is relatively concentrated with $46.3 \%$ of the athletes aged between 16 and 25 . Because the program of gymnastics is very special, most of the excellent gymnasts are 15 years old or below, accounting for $52.9 \%$. However, in order to prevent shortage and aging of the team of gymnasts in
Shaanxi Province, the foster of young gymnasts shall be strengthened. In addition, since there are relatively more gymnasts 18 years old or above, the sporting life of the athletes shall be extended as practicable as possible so as to maximize the potential of excellent gymnasts and to improve the efficiency of the cultivation of young athletes.

\subsubsection{Analysis of the Distribution Programs}

So far there are 22 kinds of programs of competitive sports carried out in Shaanxi Province. Among them swimming (diving), shooting, athletics, bowing and martial arts are the key development programs. They are also the programs that Shaanxi Province has advantages in and has obtained relatively good achievements in both national and international competitions in recent years. In the national and international competitions of recent years the performance by Shaanxi Province has been better and better (as shown in Table 3) with its achievements ranking about the tenth among the provinces of China. Though the obtaining of good achievements by Shaanxi Province has great relation with external factors, e.g. the fast development of economy and the vigorous support of the provincial leaders, the internal factors such as the reasonable arrangement of sports programs are more significant. The performance in the program of gymnastics is relatively poor.

As shown in the Table $\mathbf{4}$, there are relatively few programs of competitive sports carried out by Shaanxi Province, the scale is relatively small, and the structure of levels is not reasonable, especially for the program of gymnastics which has few top athletes, lacks reserve of talents and the technical level is low. The shortage of young gymnast has become the bottleneck to a large degree restricting the development of a top team. Therefore, it has been the top priority in Shaanxi Province to explore the development strategy and to actively extend the source and method of cultivation of backup talents in athletic gymnastics.

Table 2. Ages of high-level gymnasts in training of Shaanxi province (2014).

\begin{tabular}{|c|c|c|c|c|}
\hline Age & Below 15 & $\mathbf{1 6 - 2 5}$ & Above 25 & Total \\
\hline \hline Number & 72 & 63 & 1 & 136 \\
\hline Percentage & $52.9 \%$ & $46.3 \%$ & $0.8 \%$ & $100 \%$ \\
\hline
\end{tabular}


Table 3. List of medals won by athletes of Shaanxi province (2010-2014).

\begin{tabular}{|c|c|c|c|c|c|c|c|}
\hline \multicolumn{2}{|c|}{ Performance } & \multirow{2}{*}{2010} & \multirow{2}{*}{$\begin{array}{r}2011 \\
40\end{array}$} & \multirow{2}{*}{2012} & \multirow{2}{*}{2013} & \multirow{2}{*}{2014} & \multirow{2}{*}{$\begin{array}{c}\begin{array}{c}\text { Gymnastics in } \\
\text { Past } 5 \text { Years }\end{array} \\
2.5\end{array}$} \\
\hline \multirow{3}{*}{ National Events } & Gold Medal & & & & & & \\
\hline & Silver Medal & 23 & 17 & 31 & 26 & 42 & 4 \\
\hline & Bronze Medal & 19 & 19 & 35 & 36 & 42 & 4 \\
\hline \multirow{3}{*}{ International Events } & Gold Medal & 11 & 13 & 23 & 21 & 9 & 0 \\
\hline & Silver Medal & 8 & 10 & 6 & 10 & 5 & 0.5 \\
\hline & Bronze Medal & 3 & 2 & 2 & 9 & 4 & 2 \\
\hline \multicolumn{2}{|c|}{ Total } & 80 & 98 & 119 & 139 & 144 & 12 \\
\hline
\end{tabular}

Table 4. Part of advantage programs of Shaanxi province \& statistics of athletes in training of gymnastics (2014).

\begin{tabular}{|c|c|c|c|c|c|c|c|}
\hline Part of Advantage Programs & Diving & Shooting & Athletics & Bowing & Martial Arts & Archery & Gymnastics \\
\hline International Sports Master & 2 & 2 & 1 & 1 & 0 & 1 & 1 \\
\hline National Sports Master & 8 & 4 & 4 & 5 & 8 & 5 & 6 \\
\hline Total & 10 & 6 & 5 & 6 & 8 & 6 & 7 \\
\hline
\end{tabular}

\subsection{Analysis of Current Situation of Coaches in Athletic Gymnastics in Shaanxi Province}

The Coach plays a major role in the practice of training as the major designer, organizer and decision-maker in the training activity, thus the coach is very important in the cultivation of high-level athletes. Investigation and statistics indicates that at present there are 26 professional coaches in Shaanxi Province scattered in the training teams of all levels, 9 coaches in the adult team accounting for $34.6 \%$ and 17 coaches in the youth team accounting for $65.4 \%$. Among them there are 6 provincial coaches accounting for $23.1 \%$. It can be noticed that in general there are not enough coaches, in Shaanxi Province, for the ratio of coaches and athletes is below 1:5, lower than the national average level of 1:4. Shaanxi Province lacks coaches for the adult team especially. From the view of foster high-level backup talents, the problem of non-continuity may arise in respect of the building of coach teams in Shaanxi Province.

\subsubsection{Analysis of Professional Title}

There are 8 gymnastics coaches with senior and above titles in Shaanxi Province accounting for $30.7 \%$ among the total number of gymnastics coaches in training. Although the quality of coaches and the training level of athletic gymnastics are guaranteed to some extent in Shaanxi Province, the proportion of coaches with senior and above titles is still too small, lower than the provinces of Liaoning, Guangdong and Shandong. Among the coaches in Shaanxi Province there are just one national coach accounting for accounting for $3.8 \%$. The quantity is too small and the relative proportion is far lower than the national average level of $2 \%$. Over $80 \%$ of the coaches are of first or second level. Among them there are more first-level coaches than second-level coaches. This lays good foundation for the sus- tainable development of higher-level coaches. There are fewer third-level coaches, thus the coaches of basic level should be supplemented timely.

\subsubsection{Analysis of Academic Structure}

The cultural quality of the coaches is closely related to the cognitive level and the coaching level in the programs they are engaged in. The cultural quality of coaches not only has important influence on the growth of the athletes, but also has decisive effect on the development of overall strength of competitive sports. The academic structure of gymnastics coaches in Shaanxi Province indicates that the education level of coaches has yet to be improved, for more than $80 \%$ of the coaches are retired athletes who obtained a diploma through re-education and turned to coaches. $86.8 \%$ of the coaches have received higher education and held a degree of college or above. However, just 6 coaches have bachelor degrees and above, accounting for $23.1 \%$. This proportion is much lower than the average national level of $32 \%$. This also deviates much from the level of sportsdeveloped countries in which only $23.1 \%$ of the total, this also with more than $90 \%$ of the coaches have bachelor degree and above.

\subsubsection{Analysis of Age Structure}

As shown in the Table 5, the team of gymnastics coaches in Shaanxi Province is a vibrant and hopeful coach team. The number of coaches decreases with the rise of the age of coaches, which results in the formation of the ladder structure of age. The structure is relatively reasonable with the characteristics of youth. Most of the coaches are young. The coaches aged 45 and below account for $86.1 \%$, and the proportion of the ones aged 35 and below also reaches $52.5 \%$. The main reason for this phenomenon is the coach 
Table 5. Age structure of gymnastics coaches in Shaanxi province (2014).

\begin{tabular}{|c|c|c|c|c|c|}
\hline Age & 35 and below & $\mathbf{3 6 - 4 5}$ & $\mathbf{4 6 - 5 5}$ & $\mathbf{5 6}$ and Above & Total \\
\hline \hline Number & 14 & 8 & 3 & 1 & 26 \\
\hline Percentage & $53.84 \%$ & $30.77 \%$ & $11.54 \%$ & $3.85 \%$ & $100 \%$ \\
\hline
\end{tabular}

team is expanded through various channels in Shaanxi Province, e.g. many a large number of excellent athletes are retained as coaches after retirement and domestic outstanding young coaches are appointed. With the growth and development of the whole coach team, the age structure of the coach team has been optimized. However the experienced middle-aged coaches aged 46-55 account for only $10.7 \%$, and coaches aged above 56 also account for only $3.1 \%$. On one hand, such age structure of the coaches are conducive, for the coaches can undertake more arduous task of training and competition in modern competitive sports, innovate the means and methods of training, thus make the whole team full of potential and vitality. But on the other hand, young coaches can also increase the probability of mistakes and error in competition and training due to lack of experience.

\subsection{Analysis of Current Situation of Referees in Athletic Gymnastics in Shaanxi Province}

The team of high-level referees is the guarantee of healthy development of competitive sports. The referee is also an important part of the talent resources of athletic gymnastics. Through the investigation and analysis, by the end of 2014, Shaanxi Province has a total of 186 registered gymnastics referees at all levels, far below the total number the strong provinces in sports such as Liaoning Province, Guangdong Province and Shandong Province within which the total number can reach over 200 . Besides, there is a serious imbalance of male referees and female referees. There are 150 male referees accounting for $80.8 \%$ while there are just 36 female referees accounting for $13.2 \%$. Meanwhile there are just two national referees accounting for less than $1.2 \%$, which shows that the level of the team of sports referees in Shaanxi Province has yet to be improved. The statis- tics of the number of registered gymnastics referees in Shaanxi Province (as shown in Table 6) indicates that the number of senior referees is unbalanced and unstable, which also brings severe challenge to the development of the team of referees in Shaanxi Province.

\subsubsection{Analysis of Academic Structure}

With the rapid development of the society, academic diploma has become an indispensable and important condition of selecting and cultivating talents in various sectors of the society. Gymnastics referee is no exception, especially for high-level referees who may be required to reach certain foreign language level and to receive certain higher education. During the interview, it's noticed that a lot of high-level gymnastics referees in Shaanxi Province, constrained by the level of foreign language and education, cannot become international referees, thus losing the opportunity of enforcing the sports rules in international events. The academic structure of gymnastics referees in Shaanxi Province is as follows: the referees with diploma of college and above account for $97.2 \%$ (as shown in the Table 7). This proportion is better than that of other provinces ( $85.7 \%$ in Shandong), which shows that sports referees in Shaanxi Province are relatively educated and have some basis of quality, but the referees with high degree diploma is still too few with the ones of master degree and above accounting for only $0.4 \%$, and the ones of bachelor degree accounting for $53.6 \%$. The level of undergraduate degree and above among gymnastics referees in Shaanxi Province is consistent with the national average level. The referees with low academic degree in Shaanxi Province shall be encouraged to continue their education, and the efforts in the training of high-level, educated and top referees shall be strengthened to improve the overall quality of the team of referees.

Table 6. Number of registered gymnastics referees in Shaanxi province (2010-2014).

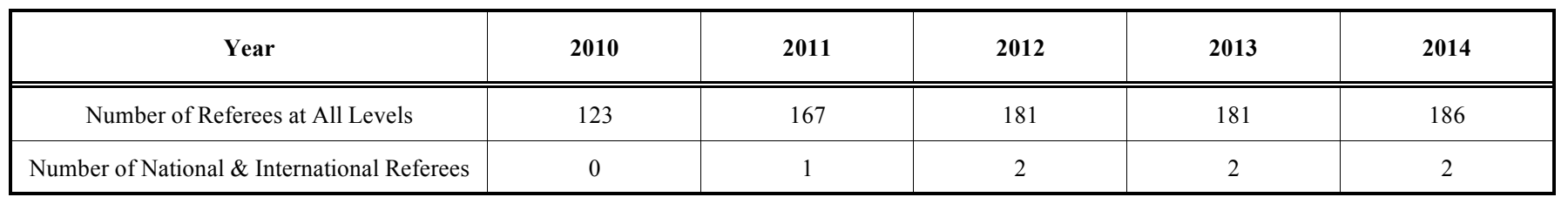

Table 7. Academic structure of referees in Shaanxi province (2014).

\begin{tabular}{|c|c|c|c|c|c|}
\hline Number & 2 & 99 & 80 & 5 & 186 \\
\hline
\end{tabular}


Table 8. Age structure of referees in Shaanxi province (2014).

\begin{tabular}{|c|c|c|c|c|c|}
\hline Age & 35 and below & $\mathbf{3 6 - 4 5}$ & $\mathbf{4 6 - 5 5}$ & $\mathbf{5 6}$ and above & Total \\
\hline \hline Number & 101 & 44 & 29 & 12 & 186 \\
\hline Percentage & $54.30 \%$ & $23.66 \%$ & $15.59 \%$ & $6.45 \%$ & $100 \%$ \\
\hline
\end{tabular}

\subsubsection{Analysis of Age Structure}

Gymnastics referees need not only rich experience in the field but also acute response and agile mind. Therefore, the priority in Shaanxi Province at the moment is to foster a group of referees of gymnastics who are of moderate age, rich experience and capability of dealing with problems reasonably. The age structure of gymnastics referees in Shaanxi Province shows the typical distribution structure of ladder. With the increase of age the number of referees wills gradually decreases. Among them there are 101 referees 35 years old or below, accounting for $54.30 \%$, which indicates the cultivation of young sports referees has been strengthened in Shaanxi Province to make the team of referees more continuous and alternative. The referees of 36-45 years old account for $23.66 \%$, referees of $46-55$ years old account for $15.59 \%$, and referees of 56 and above account for $6.45 \%$ (Table 8). In general, the age structure is relatively reasonable with the referees of 45 years old and below accounting for $77.8 \%$, which shows there is a team of relatively young referees in Shaanxi province at present.

\section{ANALYSIS OF THE DEVELOP STRATEGY OF TALENTS IN ATHLETIC GYMNASTICS IN SHAANXI PROVINCE}

The third plenary meeting of the eighteenth national representative meeting of $\mathrm{CPC}$ put forward the new requirements for the development of the national course of sports. As a new cycle of Olympic Games is forthcoming, the total demand for talents of athletic gymnastics will increase to some degree in China and the requirements for the quality and ability of talents will extremely high. All these factors bring high requirements for the efficiency of developing talents in athletic gymnastics in Shaanxi Province.

\subsection{Deepening System Reform, Strengthening Mecha- nism Innovation, Fostering Good Development for Envi- ronment for Gymnastics Talents}

There are shortcomings in the sports human resource management system of Shaanxi Province. An orderly, efficient and standardized operation mechanism of talent resources has not formed yet. Therefore, the mechanism of incentive and competition shall be established through the reform and innovation of systems to stimulate the vitality of gymnastics talents. The mechanism of training and selecting talents shall be perfected to strengthen the efforts in the cultivation of backup talents. Meanwhile the transformation of the functions and roles of sports administrative departments shall be promoted in Shaanxi Province to strive for more excellent talents for the development of sports course in Shaanxi Province and give full play to the existing talent resources.
Firstly, the mechanism of incentive and competition shall be established to stimulate the vitality of talents.

Secondly, the mechanism of training and selecting talents shall be perfected to strengthen the building of the team of backup talents.

Thirdly, the transformation of the functions and roles of sports administrative departments shall be promoted.

\subsection{Strengthening the Building of Reeducation, Reemployment, and Guarantee Mechanism for High- level Gymnast}

On one hand, the current cultural level and quality of high-level gymnasts in Shaanxi Province is relatively poor, thus reeducation of them is urgent required. On the other hand, there will be more and more high-level gymnasts who are retired waiting for arrangement after the 2012 Olympic Games. It's a very realistic problem of how to make proper arrangements for these gymnasts who has made outstanding contributions to the course of Sports in Shaanxi Province. The appropriate guarantee of these gymnasts is related to the sustainable development of athletics gymnastics in Shaanxi Province.

Firstly, to the scholarship and stipend system for athletes shall be implemented;

Secondly, the reform in the reemployment method of retired athletes shall be accelerated;

Thirdly, the occupation development plan for elite athletes shall be put on trial.

\subsection{Enhancing Exchange \& Cooperation among Talents of Athletic Gymnastics, Promoting Efficient Integration of Talent Resources}

The flow of talents in athletics gymnastics can effectively promote the reasonable distribution of sports talents, thus exerting positive impact on the development of competitive sports. Under the condition of market economy, the reasonable allocation of human resources is achieved by the market. In respect of the development strategy of sports talents in Shaanxi Province, the old ways of talent deployment by administrative method shall be changed and the mechanism for talents flow in the market shall be actively explored so that the role of the market can be given full play to enhance the competitiveness of Shaanxi Province's sports organizations in the talent market can be enhanced and to promote the development of talent resources in Shaanxi Province.

Firstly, the internal optimized allocation of talent resources within the sports system shall be enhanced. 
Secondly, the foreign exchange and international communication shall be further strengthened.

Thirdly, the establishment of relevant laws and mechanism for deploying sports talents trough the market shall be strengthened.

\section{CONCLUSION}

The development strategy of talent resources in athletic gymnastics is the overall planning of the stages and process concerning the identification, selection, education, training, configuration, employment, incentive, retaining, second or multiple occupational development of all the talent resources in athletic gymnastics within the scope of the whole society. The current situation of talent resources in athletic gymnastics in Shaanxi Province is relatively severe. It has a long way to go to truly achieve the shift from the "Big Province of Gymnastics" to the "Strong Province of Gymnastics".

\section{CONFLICT OF INTEREST}

The author confirms that this article content has no conflict of interest.

\section{ACKNOWLEDGEMENTS}

Declared none.

\section{REFERENCES}

[1] Q. Song, Development of China's Gymnastics Talent, Beijing Sports University Press, Beijing, 2004.

[2] Shaanxi Statistical Bureau, "Shaanxi Statistical Annual 2007," Chinese Statistics Press, Beijing, 2012.

[3] Shaanxi Statistical Bureau, "Shaanxi Statistical Annual 2008," Chinese Statistics Press, Beijing, 2013.

[4] Shaanxi Statistical Bureau, "Shaanxi Statistical Annual 2009," Chinese Statistics Press, Beijing, 2014.

[5] K. Fisher, J. Geenen, M. Jurcevic, K. McClintock, and G. Davis, "Applying asset-based community development as a strategy for CSR: a Canadian perspective on a win-win for stakeholders and SMEs", Business Ethics: A European Review, vol. 18, no. 1, pp. 6682, 2009.

[6] W. Liu, "Study of Current Development Situation and Development Strategy of Sports Talent Resources in Shandong Province," Qu Bu Normal University, Qu Bu: 2007.

[7] J. Zhou, "Research into Development Strategy of China's Sports talent Resources," Wuhan Sports Institute, Wuhan, 2007.

[8] M.K. Ng, "Sustainable development in the rapidly growing socialist market economy of Shenzhen: Bottom-up efforts and top-down policies", disP-The Planning Review, vol. 38, no. 151, pp. 42-50, 2002.

[9] "Sports talent resources research group of state sports general administration," Investigation and Statistics of National Sports Talent Resources, 2005.

[10] M.A. Hitt, and R. Duane, "The essence of strategic leadership: Managing human and social capital", Journal of Leadership \& Organizational Studies, vol. 9, no. 1, pp. 3-14, 2002.

Received: June 10, 2015

Revised: July 29, 2015

Accepted: August 15, 2015

(C) Jian Zhao; Licensee Bentham Open.

This is an open access article licensed under the terms of the (https://creativecommons.org/licenses/by/4.0/legalcode), which permits unrestricted, noncommercial use, distribution and reproduction in any medium, provided the work is properly cited. 